\title{
Verzeichnis der Abbildungen.
}

\section{Text-Mlustrationen.}

Fig. 1. Statuenkopf des sog. Didius Julianus in Cassel (nach ViscontiMongez) . . . . . . . . . . . . . . . . . . . 10

Fig. 2. Colossalkopf des Septimius Severus im Lourre. . . . . 26

Fig. 3. Colossalkopf der sog. Jul. Domna im Vatican (nach ViscontiMongez) . . . . . . . . . . . . . . . . . . . . . 38

Fig. 4. Büste des sog. Macrin im Louvre (nach Visconti-Mongez) . . 77

Fig. 5. Kopf des sog. Ell a g a bal im Louvre (nach Visconti-Mongez) . 85

Fig. 6. Porphyrbüste des sog. Philippus jun. im Vatican (nach Visconti-Mongez) . . . . . . . . . . . . . . . . . 148

Fig. 7. Bronzekopf des sog. Trebonian Gallus im Mus. Gregorianum (nach Visconti-Mongez) . . . . . . . . . . . . . . 159

Fig. 8. Büste des fälschlich sog. Probus in Neapel . . . . . . . 189

\section{Lichtdrucktafeln.}

I. Statue des sog. Pertin ax im Louvre.

II. Büste des sog. Pertin ax im Capitol.

III. Colossalbüste des sog. Pertinax in der Rotunde des Vatican.

IV. Büste des sog. Didius Julianus im Capitol.

V. Büste des sog. Didius Julianus im Vatican.

VI. Frauenkopf in der Samml. Jakobsen zu Kopenhagen.

VII. Büste des Pescennius Niger (?) im Capitol. VIII a.

VIII b. Statue des Clodius Albinus (?) im Vatican.

IX. Büste des fälschlich sog. Clod. Albin us im Capitol.

X. Büste des Septimius Severus im Capitol.

XI a. Büste des Septimius Severus (?) im Cupitol.

XII. Büste des Septimius Severus im Vatican.

XIII a. $\}$ Büste des Septimius Severus von Gabii im Louvre. 
XIV. Büste des Septimius Severus in München.

XV. Septimius Severus und Julia Domna am Bogen der Goldschmiede in Rom.

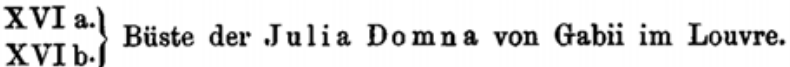

XVII. Kopf der Julia Domna von Markouna im Louvre.

XVIII a.) Büste der Julia Domna (?) im Capitol.

XIX. Frauenkopf in München.

XX a. Büste des Caracalla in Berlin.

XXI. Büste des Caracalla (?) im Capitol.

XXII a. XẌIste des Get a von Gabii im Louvre.

XXIII. Büste des Geta (?) im Capitol.

XXIV. Statue des sog. Di adumenian im Mus. Chiaramonti.

XXV. Jünglingskopf im Capitol.

XXVI. Büste der sog. Juli a Paula im Louvre.

XXVII. Portrăt-Venus im Mus. Chiaramonti (Jul. Soaemias?).

XXVIII. Colossalstatue des sog. Alexander Severus in Neapel.

XXIX. Büste des Alex. Severus in Florenz.

XXX. Kopf des Alex. Severus im Louvre.

XXXI a. Frauenkopf im Louvre (Orbiana?).

XXXII a.) Büste der Mama ea im Vatican.

XXXIII 8 (1)

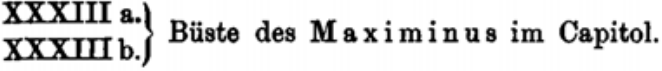

XXXIV. Büste des Maximinus (?) in Florenz.

XXXV. Bronzekopf des Balbin (?) in der vaticanischen Bibliothek.

XXXVI a.
XXXVIb. Büste des Pupien im Braccio nuovo.

XXXVII. Statue des sog. Pupien im Lourre.

XXXVIII a.) Halbfigur des Gordi a n III. von Gabii im Louvre.

XXXIX. Büste des Gordia n III. in Villa Albani.

$\mathrm{XL}$ \&. b. Büste des Philippus sen. im Braccio nuovo.

XLI. Büste des sog. Philippus sen. im Louvre.

XLII a.) Büste des Philippus sen. in Berlin.

XLIII a.) Büste der sog. Ot a cilia im brit. Museum.

XIIV. Büste der sog. Otacilia in München.

XLV. Büste des Philippus jun. (?) im Capitol.

XLVI a.
XLVI b. Büste des Trajan Decius im Capitol.

XLVII. Frauenkopf in Wien.

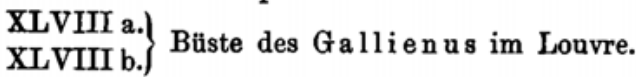


XUIX. Relief kopf der Helen a am Porphyrsarkophag im Vatican.

L. Statue Constantins des Grossen in San Giovanni in Laterano.

LI. Büste des sog. Constantin in Florenz.

LII a. Colossalkopf im Conservatorenpalast.

LIII a. Statue des sog. Julisnu s Apostata im Louvre.

LIV. Herme des sog. Julian im Capitol.

LV. Cameo in Battlesden (Julian und Helena?).

LVI. Bronzecoloss von Barletta (Theodosius d. Gr.?).

LVII. Büste des sog. Eugenius im Lourre.

\section{Münztafeln.}

I. Von Pertinax bis Caracalla.

II. Von Plautilla bis Julia Maesa.

III. Von Alexander Severus bis Pupienus.

IV. Von Gordianus III. bis Hostilianus.

V. Von Trebonianus Gallus bis Postumus.

VI. Von Leelianus bis Carinus.

VII. Von Magnia Urbica bis Constantius Chlorus.

VIII. Von Helena bis Constantin d. Gr.

IX. Von Fausta bis Honorius. 